\title{
Cyclic Testing of Steel I-Beams Reinforced with GFRP
}

\author{
O.O. Egilmez ${ }^{1}$, D. Yormaz ${ }^{2}$
}

\begin{abstract}
Flange and web local buckling in beam plastic hinge regions of steel moment frames can prevent beam-column connections from achieving adequate plastic rotations under earthquake-induced forces. This threat is especially valid for existing steel moment frame buildings with beams that lack adequate flange/web slenderness ratios. As the use of fiber reinforced polymers (FRP) have increased in strengthening and repair of steel members in recent years, using FRPs in stabilizing local instabilities have also attracted attention. Previous computational studies have shown that longitudinally oriented glass FRP (GFRP) strips may serve to moderately brace beam flanges against the occurrence of local buckling during plastic hinging. An experimental study was conducted at Izmir Institute of Technology investigating the effects of GFRP reinforcement on local buckling behavior of existing steel I-beams with flange slenderness ratios (FSR) exceeding the slenderness limits set forth in current seismic design specifications and modified by a bottom flange triangular welded haunch. Four European HE400AA steel beams with a depth/width ratio of 1.26 and FSR of 11.4 were cyclically loaded up to $4 \%$ rotation in a cantilever beam test setup. Both bare beams and beams with GFRP sheets were tested in order to investigate the contribution of GFRP sheets in mitigating local flange buckling. Different configurations of GFRP sheets were considered. The tests have shown that GFRP reinforcement can moderately mitigate inelastic flange local buckling.
\end{abstract}

\section{Introduction}

Seismic design of welded steel moment resisting frame (SMRF) connections has significantly changed after the 1994 Northridge and 1995 Kobe earthquakes. As a result of extensive investigations conducted after mid-90's, design guidelines and modification methods have been proposed for new and existing SMRF buildings (FEMA 2000a, FEMA 2000b, AISC 1999). The main objectives of these investigations were to overcome the brittle weld fractures widely observed in welded SMRFs in the aftermath of these earthquakes and to improve the plastic rotation capacities of beam to column connections. Some typical recommendations included providing a reduced beam, welded haunch, or bolted bracket modification; as well as replacing the beam flange to column groove welds with a weld metal with higher Charpy V-Notch toughness. Although brittle weld fractures can now be satisfactorily prevented for new and existing welded SMRF connections with post-Northridge design guidelines and modification

\footnotetext{
${ }^{1}$ Assistant Professor, Izmir Inst. of Technology, <ozguregilmez@iyte.edu.tr>

${ }^{2}$ Graduate Research Assistant, Izmir Inst. of Technology, <doruk_yormaz@yahoo.com>
} 
methods, mitigation of inelastic instabilities has not been completely resolved yet. Inelastic local member buckling can still prevent connections to achieve adequate plastic rotations. Okazaki, et al. (2006) and Nakashima, et al. (2002 and 2003) have investigated stability requirements for beams in steel special moment frames under earthquake induced forces and proposed more stringent limits for unbraced length and width-thickness ratios than specified in seismic design specifications to control instabilities. This threat is especially valid for existing SMRF buildings with flange slenderness ratios (FSR) exceeding the slenderness limits set forth for new buildings in current seismic design specifications.

The need to find economical and efficient ways to repair and strengthen the ailing infrastructures in US, Japan, and elsewhere has long directed the attention of researchers and engineers to fiberreinforced polymers (FRP). Past several years have seen an increased use of FRPs in strengthening and repair of steel structural members. Strengthening and repair of steel members by FRPs generally involve bonding carbon FRPs (CFRP) to the tension flange of simply supported beams or girders (ex: Miller et al. 2002, Chen and Das 2009). The high modulus of elasticity of CFRPs (similar to that of steel) makes them a viable source for such applications. A relatively newer application area of FRP-steel composite systems is the use of glass fiber reinforced polymers (GFRP) in enhancing the local stability of steel structural members. In such applications GFRPs are bonded to steel members in compression in an effort to stabilize inelastic local buckling.

The purpose of this study outlined in this paper was to investigate the cyclic behavior of steel Ibeams reinforced with GFRP at the plastic hinge region. Since inelastic local buckling is more critical in beam-column connections of existing SMRFs with beams that possess high FSR, the study specifically focused on beams with FSR exceeding the limits set forth in seismic specifications. Existing SMRFs are generally modified by a welded haunch or a reduced beam section to shift the plastic hinge away from the column face and improve their seismic performance. Hence, in order to be consistent with current practice, only beams with a triangular haunch welded to the bottom flange were investigated. Reduced beam section modification was not considered due to the fact that such an application decreases the FSR at the plastic hinge location. The study consisted of both experimental and computational studies. This paper presents results from the laboratory investigations. Results from the computational study are found in Egilmez (2009). Although the computational study included both shallow and deep beams with depth/width ratios ranging from 1.4 to 2.8 , the experimental study focused only on shallow beams. Four European HE400AA steel beams with a depth/width ratio of 1.26 and flange slenderness ratio (FSR) of 11.53 were cyclically loaded up to $4 \%$ rotation in a cantilever beam test set-up. The beams were modified by a welded haunch at the bottom flange; representing rehabilitated existing beams that did not meet the flange slenderness ratios set forth in current seismic specifications. Bare beams and beams with GFRP were tested in order to investigate the affect of GFRP reinforcement in mitigating local flange buckling. Different configurations of GFRP reinforcement were considered.

Background information and a brief summary of the findings from the computational study will be presented first, followed by an overview of the study and the description of the test setup. Results from the laboratory experiments will then be presented. The paper is concluded by a brief summary and conclusions. 


\section{Background}

Using fiber-reinforced polymers (FRP) in strengthening and repair of steel structural members has increased in the past two decades. In recent years, utilizing GFRP composite materials in mitigation of local buckling in an attempt to increase the plastic rotation capacity of steel sections has also attracted attention. In a steel-GFRP composite system the low modulus of GFRP as compared to that of steel can be an asset in stabilizing flange and web local buckling during plastic hinge formations. While the low modulus of GFRP will not allow a significant strength increase in the steel section, the flexural stiffness of the GFRP strips will enable them to provide bracing to the underlying steel, which is flowing plastically. This type of a composite action will mitigate flange and web local buckling in the plastic hinge region; provided that an early debonding or GFRP fracture do not control the behavior.

The most significant work on stability of local buckling utilizing FRP composites was a finite element based study conducted by Accord et al. (2006). Cantilever steel I-beams with GFRP strips on the compression flange were monotonically loaded. The contribution of GFRP strips to the plastic rotation capacity and flexural strength increase of the section was investigated. The plastic rotation capacity of the sections was shown to increase significantly, whereas the flexural strength increase in the sections was in the order of 20 to $25 \%$. The effects of peeling stresses were neglected in the study. Ekiz et al. (2004) conducted an experimental study investigating the energy dissipating capacity of double channel truss members. The truss members were wrapped by CFRPs around the plastic hinge region and loaded cyclically. The test results showed that CFRP wrapping could increase the size of the yielded plastic hinge region and inhibit occurrence of local buckling. Sayed-Ahmed (2004) also performed a finite element study in which CFRP strips were placed on the compression region of the web of I-beams and investigated the contribution of CFRP strips in delaying local web buckling. The results of the parametrical study showed that through the use of CFRP strips the local buckling of the web could be delayed resulting in critical load and strength increase. In a recent study, Harries et al. (2009) conducted concentric axial load tests on long and stub WT sections to investigate the ability of FRP retrofitting to affect flexural torsional buckling and web local buckling. Both carbon and glass FRPs were utilized. FRP strips were applied to the web tips of the WT sections. It was observed that the addition of small amounts of FRP had little effect on the elastic buckling behavior of long sections. However, the FRP retrofitting was able to affect web local buckling.

\section{Analytical Study}

The main goal of the analytical phase of this research program was to investigate the contribution of GFRP reinforcement on mitigating plastic local buckling on a wider range of beam sections than tested in the laboratory. Steel sections modified by a welded haunch (WH) at the bottom flange and with flange slenderness ratios (FSR) exceeding the slenderness limits set forth in current seismic design specifications were the main focus of the study. The threedimensional finite element program ANSYS (2007) was used in the analysis. A half span steel frame finite element model adopted for this study. A detailed description of the finite element model and findings can be found in Egilmez et. Al (2009).

Beam sections with three different depth/width $\left(d / b_{f}\right)$ ratios were investigated: 2.79 (deep), 2.1 (intermediate), and 1.38 (shallow). For each $d / b_{f}$ ratio three different flange slenderness ratios $(8$, 9 , and 10) that exceed the slenderness limit set forth for flanges in seismic design specifications 
were selected. Since flange and web local buckling are not independent from each other, sections with different web slenderness ratio (WSR) were examined for each flange slenderness ratio (FSR). The choice of the WSR was consistent with the available American and European wide flange sections with FSR exceeding the limit set forth in seismic design specifications.

The negative effects of peeling stresses on debonding were neglected. The analytical study initially focused on determining the optimum length, width, and location of GFRP strips in order to minimize interfacial and interlaminar shear stresses. It was shown that width wise (transverse to the longitudinal axis of the beam) the strips had to be attached to as much steel surface as possible and longitudinally the strips should extend a distance equal to the depth of the section beyond the welded haunch stiffener. GFRP reinforcement was not necessary between the column face and the welded haunch stiffener at the bottom flange. The recommended GFRP configuration is shown in Fig. 1.

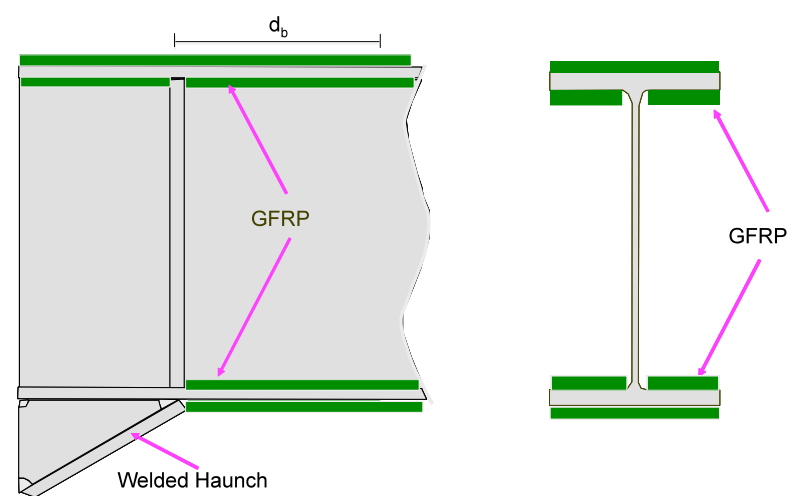

Fig. 1: GFRP Configuration used in the Analytical Study

The results of the finite element analyses demonstrated that GFRP reinforcement could provide bracing to the flanges against the occurrence of plastic local buckling and moderately improve the rotation capacities of deep beams modified by a WH at the bottom flange. For intermediate and shallow beams the GFRP reinforcement did not seem to be very effective due to the higher interfacial shear stresses that develop between the flanges and the GFRP reinforcement indicating a premature debonding. It appeared that the GFRP reinforcement would be most effective for deep beams where the bottom flange welded haunch modification is applied in an effort to moderately improve the seismic performance of the structure. For such cases the GFRP reinforcement could help the connections to maintain rotations in the order of 0.02 radians, which is required for intermediate moment frames, and may eliminate cumbersome repair works of buckled flanges and webs.

\section{Test Program}

\subsection{Test Setup}

Although previous studies have shown that steel-GFRP composite systems have good potential to be used in mitigation of plastic local buckling, no studies exist that demonstrate the actual behavior of steel I-beams reinforced with GFRP under reversed cyclic loading. In order to observe the actual cyclic behavior of steel I-beams reinforced with GFRP at the plastic hinge region a cantilever test setup was constructed at the structural engineering laboratory of Izmir Institute of Technology. The test setup and test specimen is illustrated in Fig. 2. The rigid steel 
frame shown in Fig. 2 consisted of four HD400 $\times 237$ column sections tied together with braces and beams with moment connections. In order to provide the fixed end support of the cantilever beams six HE400A beams were bolted to two of the columns of the rigid frame to form a rigid wall between these columns. A $2000 \mathrm{~mm}$ long HD400 $\times 187$ column section was then bolted to the middle of the six HE400A beams in the transverse direction. The HD400 $\times 187$ column section served as the connection column for the test specimens. The web of this column section was reinforced with doubler plates and closely spaced stiffeners to prevent shear yielding of the panel zone and local buckling. The test beams were groove welded to $50 \mathrm{~mm}$ thick steel endplates and the end-plates were bolted to the HD400 $\times 187$ column section. In practice, beamcolumn connections of SMRF do not possess end-plates and beam flanges are directly groove welded to column flanges. The purpose of the end-plates were merely to ease the test program. An alternative to end-plate connection detail was to groove weld each beam to different column members, which would have required panel zone strengthening for each column member. By providing an end-plate detail, repeated cumbersome panel zone strengthening applications were omitted. During testing the rotation of the connection was recorded by displacement transducers, as will be explained later in the paper, and were subtracted from the total tip rotation measured to calculate the actual beam tip rotation.

A displacement controlled MTS loading system was used to provide the cyclic loading. The beam end was clamped to a 50-ton actuator, which provided quasi-static cyclic loading with increasing displacement amplitudes. A swivel joint was attached to the top of the actuator to permit free motion of the beam end. The test specimens were loaded with the average rotation velocity of $1.7 \times 10^{-4} \mathrm{rad} / \mathrm{s}$ (corresponding to $0.5 \mathrm{~mm} / \mathrm{s}$ actuator ram velocity).

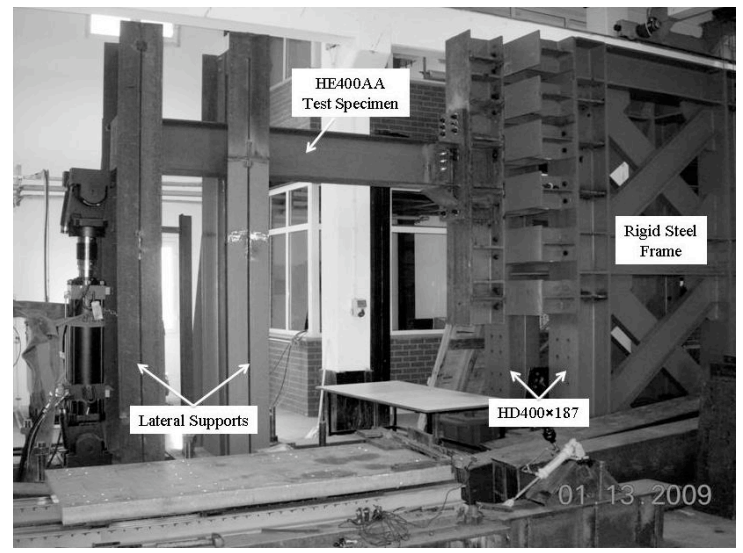

Fig. 2: Photograph of Test Setup and HE400AA Test specimen

\subsection{GFRP Application}

Small scale laboratory tests confirming to ASTM standards were conducted to determine the compression, tension, and interlaminar shear strength of the GFRP material used, as well as the interfacial shear strength of the bond surface between beam flanges and GFRP strips (Guven 2009). E-glass woven fabric with $0^{\circ} / 90^{\circ}$ fiber orientations provided from Telateks Textile Products Company were used as the reinforcement material and DTE-1000 epoxy resin provided by DURATEK Co. was used as the matrix element for GFRP applications. The tensile strength and specific weight of the fibers given by the manufacturer were $2500 \mathrm{MPa}$ and $1250 \mathrm{gr} / \mathrm{m}^{2}$, respectively. Hand lay-up technique was used to produce GFRP specimens for the small-scale 
tests. The tensile, compressive, and interlaminar shear strength of GFRP were measured to be 375, 224, and $13 \mathrm{MPa}$, respectively. The primer used in this study was silane; a chemical compound prepared in laboratory conditions. Silane compound consisted of $20 \%$ ethanol, $80 \%$ deionized water, sufficient acidic substance that brings the $\mathrm{Ph}$ of the ethanol-deionized water mixture, and $1 \%$ of Gglycidoxypropyltrimethoxysilane. The only disadvantage of the silane primer was that it had to be cured for one hour at $80^{\circ} \mathrm{C}$. The interfacial shear strength of the bond surface was measured to be $11.0 \mathrm{MPa}$.

Direct wet lay-up technique was used to apply glass fabric to the plastic hinge region of the test specimens. The surface of the steel was first grinded and sand blasted to remove any dust, paint, and rust and cleaned with acetone afterwards. Silane primer was applied to the surface next. The plastic hinge region was then contained by $50 \mathrm{~mm}$ thick glass wool panels and kept at $80^{\circ} \mathrm{C}$ for one hour by electrical heaters. The glass fabric layers were then applied to the plastic hinge region. Each layer was saturated with epoxy resin and rolled with rollers to remove the trapped air between the layers. Curing agents were added to the epoxy resin to allow for sufficient gel time to finish the GFRP application. The glass fabric layers were than clamped between wooden plates to ensure an even and dense saturation was obtained. GFRPs were cured in room temperature for a week before testing. Fig. 3 shows a photograph of the GFRP application.

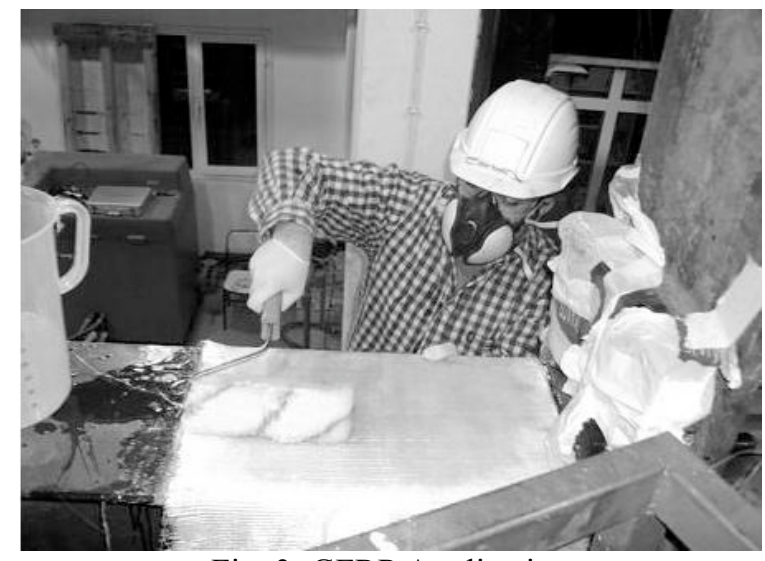

Fig. 3: GFRP Application

\subsection{Test Specimens}

A total of four cantilever beam tests were conducted. The section used in these tests was a European HE400AA section. The lengths of the beams were $3000 \mathrm{~mm}$. The measured tensile properties of the HE400AA section, averaged from three tension tests on standard coupons (ASTM 2003), are presented in Table 1. Although an EN10025-2 Grade S355 steel was ordered, the measured properties of the section were above the expected properties of a grade S355 steel. The measured dimensions and plastic moment capacities of the sections are presented in Table 2. The flange slenderness ratio $(b / t)$ of the beams was 11.53. Limiting slenderness ratio for compact and seismically compact flanges are 8.35 and 6.59, respectively (AISC 2005c and AISC 2005a), for $F_{y}=414 \mathrm{MPa}$ (yield strength of flanges of the test beams).

Beam flange to end-plate groove weld details were identical in all four test specimens. These welds were made using Oerlicon $3 \mathrm{~mm}$ diameter electrode with a tensile strength of $600 \mathrm{~N} / \mathrm{mm}^{2}$. This electrode has a minimum Charpy $\mathrm{V}$-notch $(\mathrm{CVN})$ rating of $27 \mathrm{~J}$ at $-29^{\circ} \mathrm{C}$. This $\mathrm{CVN}$ rating 
is required by the current AISC Seismic Provisions for Steel Buildings (AISC 2005a). Backing bars were removed at both top and bottom flange grove welds, and a reinforcing fillet was placed at the location of the removed bar. All four connections were ultrasonically tested against any weld defects.

Table 1: Standard Tensile Coupon Test Results for HE400AA Section

\begin{tabular}{cccc}
\hline Location & $\begin{array}{c}\text { Yield Strength } \\
(\mathrm{MPa})\end{array}$ & $\begin{array}{c}\text { Ultimate Strength } \\
(\mathrm{MPa})\end{array}$ & \% Elongation \\
\hline Top Flange & 413.1 & 487.1 & 42.0 \\
Web & 436.1 & 520.7 & 33.8 \\
Bottom Flange & 414.8 & 488.4 & 42.6 \\
\hline
\end{tabular}

Table 2: Actual Dimensions and Plastic Moment Capacity for HE400AA Section

\begin{tabular}{ccccccccc}
\hline $\begin{array}{c}\mathrm{h} \\
(\mathrm{mm})\end{array}$ & $\begin{array}{c}\mathrm{b}_{\mathrm{f}} \\
(\mathrm{mm})\end{array}$ & $\begin{array}{c}\mathrm{t}_{\mathrm{w}} \\
(\mathrm{mm})\end{array}$ & $\begin{array}{c}\mathrm{t}_{\mathrm{f}} \\
(\mathrm{mm})\end{array}$ & $\begin{array}{c}\text { Web } \\
\text { Slenderness } \\
\text { Ratio }\end{array}$ & $\begin{array}{c}\text { Flange } \\
\text { Slenderness } \\
\text { Ratio }\end{array}$ & $\begin{array}{c}\mathrm{Z}_{\mathrm{w}} \\
\left(\mathrm{mm}^{3}\right) \\
\mathrm{x} 10^{3}\end{array}$ & $\begin{array}{c}\mathrm{Z}_{\mathrm{f}} \\
\left(\mathrm{mm}^{3}\right) \\
\mathrm{x} 10^{3}\end{array}$ & $\begin{array}{c}\mathrm{M}_{\mathrm{p}} \\
(\mathrm{kN}-\mathrm{m})\end{array}$ \\
\hline 381 & 302 & 9.8 & 13.2 & 38.9 & 11.4 & 414 & 1466 & 786.4 \\
\hline
\end{tabular}

Triangular haunches cut from a HD400 $\times 187$ section was welded to the bottom flange of the HE400AA sections. The dimensions of the triangular haunches were $220 \mathrm{~mm}$ and $160 \mathrm{~mm}$ in the longitudinal and vertical directions, respectively. AISC (1999) recommendations were followed in the welded haunch modification. The main objective of the welded haunch modification was to observe the contribution of GFRP reinforcement on a modified existing welded steel moment connection for seismic resistance. All of the specimens were provided with a shear tab welded to the $50 \mathrm{~mm}$ plates and bolted to the beam webs. Four M24 (24 mm diameter) Grade $10.8\left(F_{u}=\right.$ $785 \mathrm{MPa}$ ) bolts were used at all connections.

A total of four cantilever beam tests were conducted. Three of the specimens were reinforced with GFRP. In addition to the GFRP reinforced specimens, one bare beam specimen was also tested in order to compare the behaviors of bare and reinforced specimens. The optimum GFRP configuration (Fig. 1) determined in the analytical phase of the research study was adopted in the test program. In order to minimize interfacial and interlaminar shear stresses, GFRPs were applied over the entire width of the flanges. At the top flange GFRP application started from the face of the end-pate and extended $400 \mathrm{~mm}$ (depth of the section) beyond the welded haunch stiffener. At the bottom flange GFRP application commenced from the face of the welded haunch stiffener. The total length of the bottom flange GFRP reinforcement was also $400 \mathrm{~mm}$. The parameters that were changed in the tests included the thickness of the GFRP, web reinforcement, and the continuity of GFRP around the flanges. The four specimens were labeled as B, G1, G2, and G3. Specimen B was the control specimen with no GFRP attached. In specimen G1, glass fabrics were wrapped around the flanges as a single sheet, providing continuity between the top and bottom of the flanges. In specimen G2, wider glass fabrics were utilized and the entire beam section was wrapped as one piece, also covering the two sides of the web. In specimen G3, separate glass fabric sheets were bonded to the top and bottom of the flanges. Similar to the web of specimen G1, the web of specimen G3 was also not reinforced. The number of glass fabric layers utilized in each specimen was 3 for specimens G1 and G2, and 5 for specimen G3. Hence, the total thickness of the GFRP reinforcement was $6 \mathrm{~mm}$ for specimens G1 (3 $\mathrm{mm}$ on each side of the flanges) and G2 (3 $\mathrm{mm}$ on each side of the flanges and 
the web), and $10 \mathrm{~mm}$ for specimen G3 (5 mm on each side of the flanges). Fig. 4 and 5 show the different GFRP configurations used in the four HE400AA specimens.
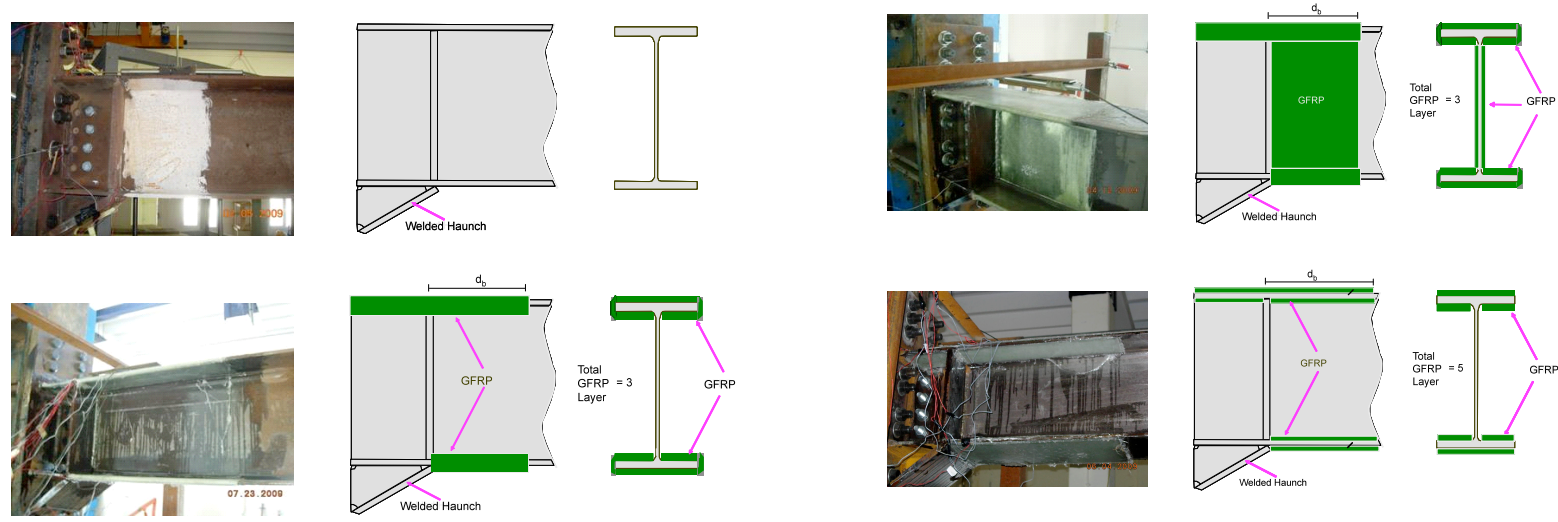

Fig. 4: Specimen Bare (top) and Specimen G1 (Bottom)
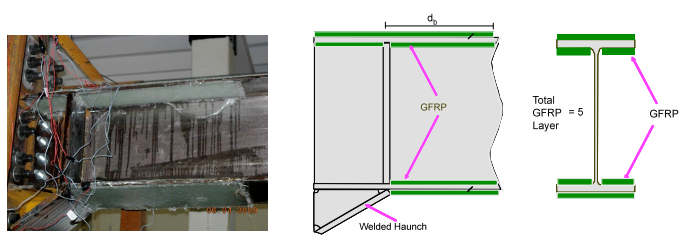

Fig. 5: Specimen G2 (top) and Specimen G3 (bottom)

It was previously mentioned that the reason for investigating beams with a bottom flange triangular welded haunch was to be consistent with current practice. In welded haunch modification of existing SMRFs, single welded haunch applied only to the bottom flange is generally preferred over addition of haunches to both top and bottom flanges. Addition of a haunch to the top flange requires the removal of the floor slab. From this perspective, applying GFRP to the top flange will be quite challenging in the field. Attaching GFRPs to beams of existing SMRF will also require the removal of fireproofing for both flanges. However, the analytical study (Egilmez, 2009) conducted as part of the this research investigation has shown that GFRP reinforcement has good potential to mitigate local buckling and help connections to maintain rotations in the order of 0.02 radians, which is required for intermediate moment frames, and may eliminate cumbersome repair works for buckled flanges. Hence, for SMRFs where the bottom flange welded haunch modification is applied in an effort to moderately improve the seismic performance of the structure, cumbersome field works prior to applying GFRP to the flanges could be justified. In addition, this study is also of importance in improving the understanding of the cyclic behavior of steel-GFRP hybrid systems.

\subsection{Measurements}

The actuator possessed a built in displacement transducer and load cell. Each specimen was instrumented with three displacement transducers and several strain gages. The three displacement transducers recorded the displacements of the tip of the beam and the end plate above and below the top and bottom flanges, respectively The panel zone of the HD400×187 column section was also instrumented with strain gages and displacement transducers to verify that it remained elastic during the cyclic loading.

\subsection{Loading Protocol}

The loading protocol defined in AISC (2005b) for cyclic tests of beam-to-column moment connections in SMF and IMF was adopted. Due to the unpredictable small displacements in the steel frame and the beam-column bolted connection, slight deviations from the AISC (2005b) loading protocol were inevitable during testing. Fig. 6 shows the load steps applied to the four specimens. The higher load steps of specimens B and G3 were approximately $10 \%$ off the loading protocol defined in AISC (2005b) due to a miscalculation in the displacement inputs 
required by the electrical control unit of the MTS loading system. However, a comparison of the behaviors of the reinforced specimens with that of the bare specimen was still possible.
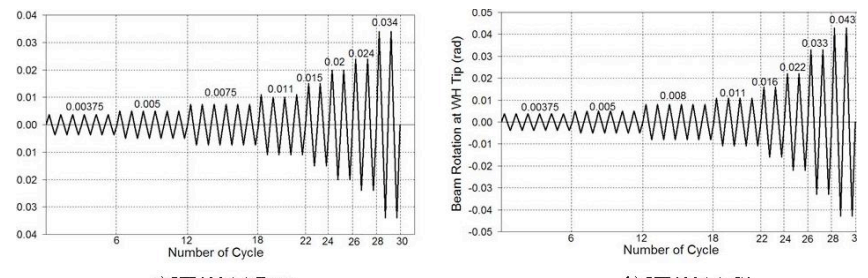

a) HEA00AA Bare
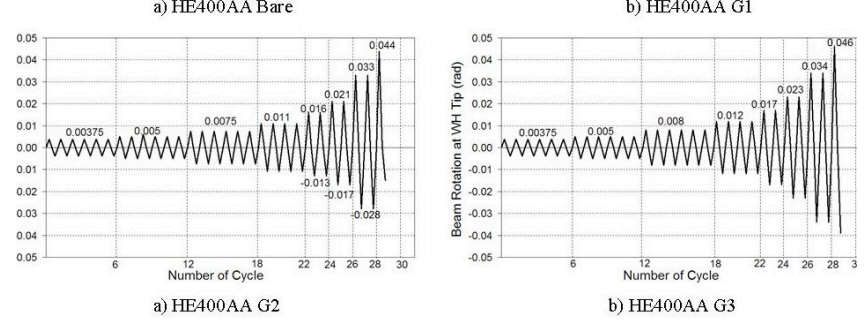

Fig. 6: Loading Sequences followed in the Cyclic Tests

\section{Test Results}

Load versus beam tip rotation relationships for all four HE400AA specimens are shown in Fig. 7. These plots include a normalized moment axis, where $M$ is the moment at the face of the welded haunch stiffener, and $M_{p}$ is the full section plastic moment of the beam based on the actual yield stresses presented in Table 2. Beam tip rotation is also calculated with respect to the face of the welded haunch stiffener. Proper strain readings from the diagonal of the welded haunches could not be obtained. Therefore, the moment at the column face, which should be less than the moment at the face of the stiffener, was not calculated. Positive rotations in the plots imply that the top flange was in compression.

For the bare specimen the maximum $M / M_{p}$ values were 1.06 and 1.04 for positive and negative bending, respectively. These values were 1.09 and 1.06 for the G1 and G2 specimens and 1.04 and 1.07 for the G3 specimen. In all of the specimens yielding initiated at about $1.2-1.3 \%$ beam rotation. The bare beam test was stopped at the end of the second cycle of $-3.5 \%$ rotation due to malfunctioning of the hydraulic pump. Therefore, the failure mode of the bare specimen could not be observed. Two of the reinforced specimens (G2 and G3) failed due to the fracture of the top flange around the heat-affected zone adjacent to the top flange groove weld. Specimen G1 completed the two cycles of $4.2 \%$ rotation. The test was stopped at this point.

In all of the specimens top flange local buckling (LB) was concentrated inside the welded haunch zone adjacent to the column face. In the bare specimen top flange LB was first visually observed at the $2^{\text {nd }}$ cycle of $2.4 \%$ rotation. Top flange LB was clearly visible at the $1^{\text {st }}$ and $2^{\text {nd }}$ cycles of $3.4 \%$ rotations as the severity of buckling gradually increased. At the G1 specimen, top flange local buckling was first observed at the $1^{\text {st }}$ cycle of $2 \%$ rotation. The severity of the buckling increased as the rotations gradually increased. Photographs showing the stages of top flange local buckling of the bare and G1 specimens are shown in Fig. 8. Bottom flange LB was concentrated outside the welded haunch zone, adjacent to the face of the stiffener, for all specimens. No bottom flange LB was observed inside the welded haunch zone. In the bare specimen, bottom flange LB was first observed at the $1^{\text {st }}$ cycle of $-2.6 \%$ rotation; whereas LB of 
the bottom flange was first observed in the $1^{\text {st }}$ cycle of $-3.1 \%$ rotation in the reinforced specimens. The severity of LB increased in all specimens as the rotations amplified. Photographs of bottom flange LB of the bare and G1 specimens at different rotation amplitudes are shown in Fig 9. It should be noted that the observations herein mentioned were all visual. However, it is clear from the photographs that the bottom flange buckling of the bare specimen at a rotation of $3.5 \%$ was much more severe than the buckling observed in the G1 specimen at a rotation of $4.2 \%$.

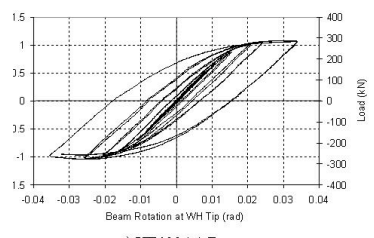

a) HE400AA Bare

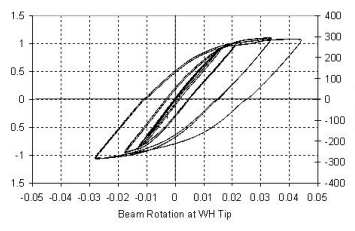

a) $\mathrm{HE} 400 \mathrm{AA}$ G2

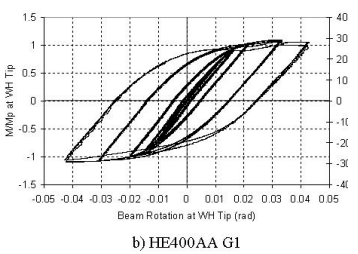

b) HFA00AA G1

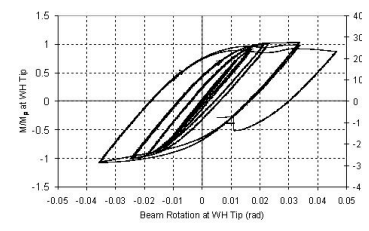

b) HE400AA G3

Fig. 7: M/M $\mathrm{M}_{\mathrm{p}}$-Beam Tip Rotation Plots of Specimens
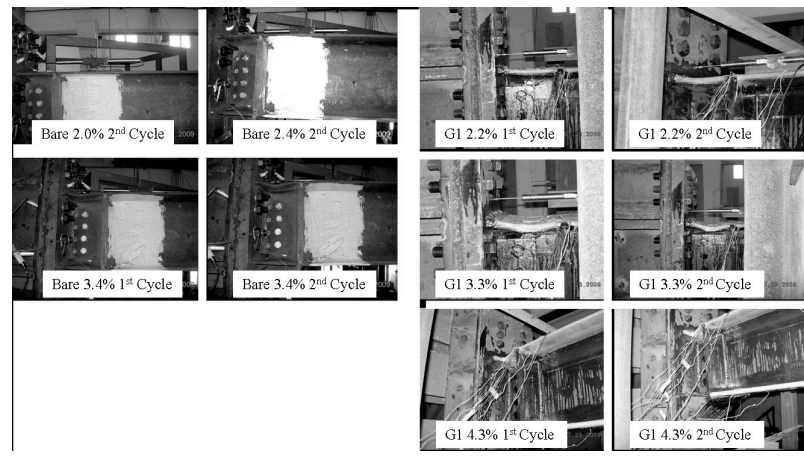

Fig. 8: Photos of Top Flange LB for Spec. B and G1
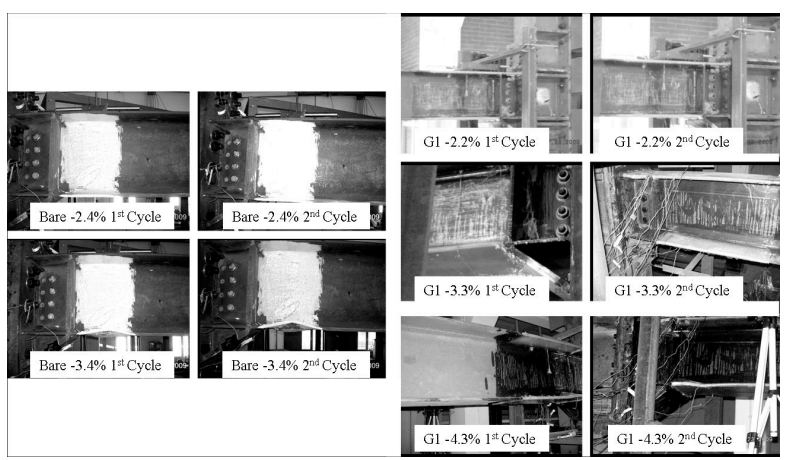

Fig. 9: Photos of Bottom Flange LB for Spec. B and G1

Figs. 10 shows a comparisons of the $M / M_{p}$ versus beam tip rotation plots of specimen G1 with specimens B, G2, and G3, respectively. It can be observed from Fig. 10 that for positive bending the behavior of specimens G1 and B are almost identical. This is probably due to the fact that top flange local buckling is concentrated at the face of the column and debonding takes place prior to the initiation of local flange buckling. From the strain measurements it was observed that debonding occurred at a rotation amplitude of about 1.5\%. However, local buckling at the top flange was not observed until $2 \%$ rotation. The contribution of GFRP reinforcement can be seen in negative bending. In negative bending the load carrying capacity of the bare beam $\left(M / M_{p}\right)$ started to drop after reaching a maximum value of -1.04 at a beam tip rotation of $-2.5 \%$. The capacity dropped to -0.95 at a rotation of $-3.5 \%$. The load drop is consistent with the severe bottom flange local buckling observed at this rotation (Fig. 9). On the other hand, specimen G1 continued to carry the load up to a beam tip rotation of $-4.2 \%$. The maximum normalized moment recorded was -1.06 at the $1^{\text {st }}$ cycle of $-4.2 \%$. The normalized moment dropped slightly $\left(M / M_{p}=-1.03\right)$ at the $2^{\text {nd }}$ cycle of the $-4.2 \%$ rotation. The photographs of the buckled bottom flanges shown in Fig. 9 also show the positive contribution of the GFRP reinforcement. 


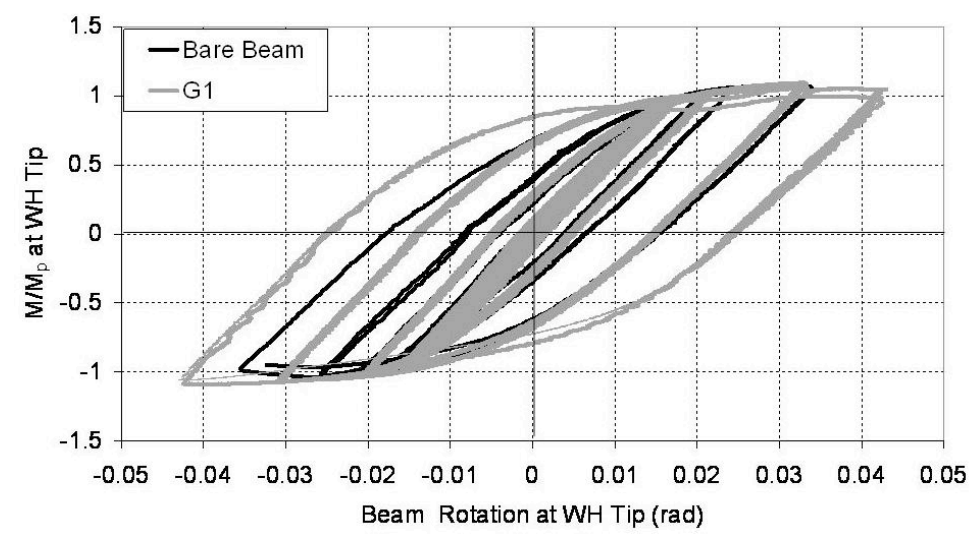

Fig. 10: Comparison of $\mathrm{M} / \mathrm{M}_{\mathrm{p}}$-Beam Tip Rotation plots of Specimens $\mathrm{G1}$ and $\mathrm{B}$

Although not shown here comparing the behavior of specimens G1 and G2 shows that attaching GFRP to the web of the beam does not have a specific contribution to the behavior. The hysteresis cycles of both specimens were almost identical. Neither of the specimens showed significant web buckling. Comparing the behavior of specimens G1 and G3 reveals that attaching the glass fabrics as a single sheet to the top and bottom flanges continuously rather than as separate sheets to the top and bottom of the flanges resulted in a slightly better performance. The load carrying capacity of specimen G3 started to drop at the $2^{\text {nd }}$ cycle of $3.4 \%$ rotation; whereas the load carrying capacity of specimen G1 started to drop at the $2^{\text {nd }}$ cycle of $4.2 \%$ rotation. This was probably due to the fact that the separate sheets of specimen G3 did not function as well as the continuous sheets of specimen G1. The same behavior was also observed at the bottom flange during the $2^{\text {nd }}$ cycle of $-3.4 \%$ rotation.

\section{Conclusions}

This paper presented results from the experimental phase of a research study investigating the plastic local buckling behavior of modified existing steel beams reinforced with GFRP in the plastic hinge region. The modification consisted of a bottom flange triangular welded haunch. The HE400AA specimens tested in the experimental phase of this research study cover only a fraction of the sections analyzed in the computational phase. The capacity of the loading system and the high flange slenderness ratio required limited the depth of the sections that could be tested. The analytical study focused on sections with depth/width ratios of 2.79 (deep), 2.1 (intermediate), and 1.38 (shallow); whereas the depth/width ratio of the HE400AA section was 1.26 .

Based on the results of both the experimental and analytical research reported on herein and Egilmez (2009), it appears that the addition of longitudinally oriented GFRP reinforcement to the top and bottom flanges of the plastic hinge region of steel I-beams subjected to cyclic loading may serve to effectively brace the flanges against the occurrence of plastic local buckling during plastic hinging. This type of a behavior will result in an increase in the moment carrying capacity of the beams; as well as an increase in their energy dissipation capacity. The results indicated that GFRP reinforcement would be most effective for deep beams and can help the sections to maintain rotations in the order of 0.02 radians, which is required for intermediate moment frames. 
While the results from this work have shown that GFRP reinforcement has good potential to be used in rehabilitation of existing steel beam-column connections to serve in seismic zones that require intermediate moment frames, it should be noted that quasi-static loading was applied to the specimens and the actual behavior of the interface of the steel-GFRP composite action under dynamic loading need to be investigated. A more detailed experimental program would be required to develop any specific design recommendations.

\section{Acknowledgments}

The writers gratefully acknowledge the funding provided by The Scientific and Technological Research Council of Turkey (TUBITAK). Partial funding from a reintegration grant provided by the European Commission and Izmir Institute of Technology is also acknowledged.

\section{References}

Accord, N. B., and Earls, C. J. (2006). "Use of fiber-reinforced polymer composite elements to enhance structural steel member ductility," J. of Composites for Construction, ASCE, 10 (4) 337-344.

American Institute of Steel Construction (AISC). (2005a). Seismic provisions for structural steel buildings, ANSI/AISC 341-05, AISC, Chicago, IL.

American Institute of Steel Construction (AISC). (2005b). Prequalified connections for special and intermediate steel moment frames for seismic applications, ANSI/AISC 358-05, AISC, Chicago, IL.

American Institute of Steel Construction (AISC). (2005c). Specification for structural steel buildings, ANSI/AISC 360-05, AISC, Chicago, IL.

American Institute of Steel Construction (AISC). (1999). Modification of existing welded steel moment connections for seismic resistance, Steel Design Guide Series 12, AISC, Chicago, IL.

ANSYS Inc. (2007). Finite element model users manual, Version 11.0, Canonsburg, Pa.

American Society for Testing and Materials (ASTM). (2003). "Standard test method for tension testing of metallic materials (Metric)," ASTM, Designation 03 .01: E 8M.

Chen, M. and Das, S. (2009). "Experimental study on repair of corroded steel beam using CFRP," Steel and Composite Structures, TECHNO PRESS, 9 (2) 103-118.

Egilmez, O. O., Alkan, D., and Ozdemir, T. (2009). "Cyclic behavior of steel I-beams modified by a welded haunch and reinforced with GFRP," Steel and Composite Structures, TECHNO PRESS, 9 (5) 419-444.

Ekiz, E., El-Tawil, S. Parra-Montesinos, G., and Goel, S. (2004). "Enhancing plastic hinge behavior in steel flexural members using CFRP wraps," Proceedings of the 13th World Conference on Earthquake Engineering, Paper No. 2496, Vancouver.

Federal Emergency Management Agency (FEMA). (2000a). Recommended seismic design criteria for new steel moment-frame buildings, FEMA 350, Washington, D.C.

Federal Emergency Management Agency (FEMA). (2000b). Recommended seismic evaluation and upgrade for existing welded steel moment-frame buildings, FEMA 351, Washington, D.C..

Harries K. A., Peck, A. J., Abraham, E. J. (2009). "Enhancing stability of structural steel sections using FRP," Thin Walled Structures, ELSEVIER, 47 (10)1092-1101.

Miller, T. C., Chajes, M. J., Mertz, D. R., and Hastings, J. N. (2002). "Strengthening of a steel bridge girder using CFRP plates," Journal of Bridge Engineering, ASCE, 6 (6) 514-522.

Nakashima, M., Kanao, I., and Liu, D. (2002). "Lateral instability and lateral bracing of steel beams subjected to cyclic loading," J. of Structural Eng., ASCE, 128 (10), 1308-1316.

Nakashima, M., Liu, D., and Kanao, I. (2003). "Lateral-torsional and local instability of steel beams subjected to large cyclic loading," J. of Steel Structures, 3 (3), 179-189.

Okazaki, T., Liu, D., Nakashima, M., and Engelhardt, M.D. (2006). "Stability requirements for beams in seismic steel moment frames," J. of Structural Eng., ASCE, 132 (9), 1334-1342.

Sayed-Ahmet, E.Y. (2004). "Strengthening of thin-walled steel I-section beams using CFRP strips," Proceedings of the 4th Advanced Composites for Bridges and Structures Conference, Calgary, Canada. 